\title{
Why Do We Need Minorities Among Our Faculty?
}

\section{William Yslas Vélez}

\section{Note: The opinions expressed here are not necessarily those of Notices.}

Many years ago, when I was just beginning in our profession, the southwestern university that I was visiting had no Chicano $^{1}$ faculty in the mathematics department, a common state of affairs even now. I asked the head of the mathematics department at the time why they had no Chicano faculty, and his answer was, "Why do we need one?"

Have departments asked themselves this question: Why do we need minority faculty? In my forty years as a faculty member I never witnessed substantive faculty deliberations on this topic. Of course, there are obvious answers to this question. The lack of minority faculty speaks to the failure of our educational system to educate the US population. Why is it that there are so few minority students in our graduate programs in mathematics? This represents a failure of our departments to attract minority students to the study of mathematics. Is this intentional or is it simply not a concern that comes up in departmental discussions [2]?

When I was a child growing up in Tucson, our Catholic church was staffed with priests from Spain and Ireland. Their mission was to convert or re-make the Mexicans and Indians of the Southwest in their own image. Could mathematics departments be viewed as such missionaries? Their faculty commonly do not look like the native populations they are supposed to be educating.

William Yslas Vélez is emeritus professor of mathematics at The University of Arizona. His email address is velez@math . arizona. edu.

${ }^{1}$ At that time, Chicano meant Mexican-American, though with an activist connotation.

For permission to reprint this article, please contact:

reprint-permission@ams.org.

DOI: http://dx.doi.org/10.1090/noti1742
I do not think that mathematicians view their role as one of motivating their students to join them. ${ }^{2}$ Then, what is the role of these faculty? Gatekeepers? Dedicated Guardians of Mathematical Knowledge?

"Why do we need one?" If mathematics departments were research institutes, with only one goal, the production of mathematical knowledge, then I could see a monklike existence for mathematics departments. We sit and meditate, think deep thoughts, separated from the local community.

But we are not research institutes. Mathematics departments are part of a university, a teaching university, with students! The goal of a university is multi-faceted. Not only does it produce knowledge, it now patents it. It is linked to the world. It has goals. And a mathematics department's activities and hiring practices should be linked to those goals: effective teaching, the use of technology in teaching and diverse teaching methods, outreach to the community, the promotion of career opportunities for its students, scholarly endeavors, and research with students. This complexity of activities necessitates a more diverse and caring workforce. Yes, I said caring.

Professional meetings are an important part of our profession. We cannot minimize the importance of faceto-face conversations among our colleagues. As scholars we address many issues. As we participate in conferences, conversations spark thought and launch us into new directions, provide insights that we were searching for. So it was at a recent meeting of Transforming Post-Secondary Education (TPSE) held at Worcester Polytechnic Institute. Conversations there gave me a better answer than the one I presented in [4] to why we need diverse faculty.

2See [1] for examples of how departments can have productive discussions on motivating their students. 
During a session on equity, Maria Mercedes Franco of Queensborough Community College, originally from Colombia, mentioned that in Hispanic interactions there are laughter and smiles, handshakes and hugs. I understood Maria's comments as indicating that there is a cultural divide between students and faculty at our universities. We all know this though we don't talk about it. My own belief is that one of the unfortunate current hidden functions of a mathematics department is to change the culture of the mathematics majors, to make mathematics majors become like the faculty. I decided to earn a $\mathrm{PhD}$ in mathematics in 1965, in my second year of undergraduate studies at The University of Arizona. This was not a friendly place for Mexican-Americans. It has been my experience that mathematics departments ignore the culture of the local community. One attends mathematical functions, and if there is music it is classical. Physically, what does a mathematics department look like? Is there any part of the local community that is reflected in the department? There are 21 Native American reservations in the state of Arizona. Our universities are built on the lands of these Native peoples. When one walks into a mathematics department, is there any indication of the rich culture of the local communities?

Maria's comments point to the interactions between individuals in our mathematics departments, and this ties into a comment that Uri Treisman made during the conference. I have written about my efforts to recruit students into the mathematics major by inviting them to add the mathematics major [4]. Uri commented that this was a very wise tactic. Though it was kind of him to say that, it is not correct. It is not wise. It is cultural.

When I was a child, when someone walked into our home, my mother would say, "Saluda, mi hijito" (Say hello, my dear son). As a young professor, perhaps I did not heed these words. I had been acculturated in the way a mathematician behaves. However, no matter what I did, I was often viewed as a minority mathematician. At a math party that was held at my home, one of the graduate students had a bit too much to drink and told me that the only reason that I was hired was because I was a minority. With time, I began to see my value to the department as a Chicano mathematician. With time my upbringing won out over this attempt to make me fit the mold.

Now, when a student comes into my office, I listen to those words, "Saluda, mi hijito." I extend my hand and a welcome. I want to share my good fortune with others. I decided to study mathematics and it greatly enriched my life. Because of that upbringing, I invite students to study mathematics. This is not a wisdom. It is culture.

Even though I was brought up in the Mexican culture, I am not promoting the view that Hispanics are better suited to educate the next generation of students. The characteristic, the ability to care and to motivate others to join us in mathematical studies, is not restricted to one culture. I have used the word "minority" because I think that those of us in the minority community who have managed to be successful in this profession bring not only cultural elements, but also a recognition of the struggles that US students have gone through to get to the university. Our experiences, plus our culture, make us a valuable asset to the profession. We bring to the workplace a different dynamic, a different interaction with students [1]. Given the importance of mathematical training for our current workforce and the dramatic changes in the make-up of the student populations, minority faculty are needed now more than ever.

In 1974, as a fourth year graduate student at The University of Arizona, I had the opportunity to be an intern at Bell Labs. What an amazing mathematical experience that was! At the end of the summer a recruiter came to see me and asked if I would be interested in applying for a position upon completing my $\mathrm{PhD}$ the following year. My response was visceral: "I would not work here if it was the last place on earth. This is the coldest bunch of people I have ever been with."

That was an incredibly sad response. I denied myself an absolutely amazing mathematical experience. Yet, that was my reaction. I grew up in the warm cultural embrace of the Mexican-American community in Tucson, and the cultural divide that I felt was not one that I thought I could live with.

I believe that this is all too common. How many students from all walks of life, men and women, have turned away from the study of mathematics because of the mathematical culture that is so impersonal? It does not have to be this way. Just because we are serious about what we are doing does not mean we should be somber.

That is why we need minority and female faculty. It is not just the production of mathematics that goes on in a department. There is also an acculturation process and it is this that needs diversification. It is time for our graduate programs to place more emphasis on recruiting and retaining minority students. It is especially important for the top 20 graduate programs in mathematics to take the lead in this effort.

How are these graduate programs going to succeed in recruiting a diverse student body while affirmative action is again under attack? How do we defend bringing in a diverse student body while at the same time saying that we have recruited the best?

\section{The Problem is the Word "Best."}

1. Do we mean best in terms of GRE scores and GPAs? Anyone who has run a graduate program knows that these are poor indicators of student success. As mathematicians, we value creativity; yet in determining whom to admit we evaluate only knowledge.

2. Does best mean what is best for the faculty? The more prepared a student is the less that we have to teach them.

3. Could best be taken to mean what is best for the nation? Wouldn't educating a diverse workforce produce a faculty better able to connect with the US population? Is it really best for our nation that half of our PhDs in mathematics are international?

4. It may come as a surprise to graduate programs but our graduates do not all become mathematical researchers. What are the best characteristics in an applicant to link to the many job opportunities that are now available? 
The above points are in line with a recent publication [3], where the summary states: "Over the course of their education, graduate students become involved in advancing the frontiers of discovery, as well as in making significant contributions to the growth of the US economy, its national security, and the health and well-being of its people."

As a start, I would like to pass on to all of my colleagues the wisdom that my mother passed on to me. "Say hello, my dear child." "Saluda, mi hijito." "Saluda, mi hijita."

\section{References}

1. William YSLAS VéLEz, Each one, teach one, Science (9 July 2004). www. sciencemag.org/careers/2004/07/each-one -teach-one,

2. WILLIAM YSLAS VÉLEZ, Inreach is the new outreach, MAA FOCUS (August/September 2015), pp. 4-5.https://tinyurl.com /ybbu64ps.

3. Graduate STEM Education for the 21st Century, National Academies of Science, Engineering and Medicine, 2018. https:// tinyur 1. com/y9fks6mf.

4. WILLIAM YSLAS VÉLEZ, The role of academic departments in diversity issues, Science, (12 March 2004). https://tinyur1 .com/y6ujsee4.

Photo Credit

Author photo courtesy of William Yslas Vélez.

\section{ABOUT THE AUTHOR}

After 50 years at The University of Arizona (UA), nine as a student and 41 as member of the faculty, Bill stepped down. Bill has high hopes that his interest in promoting the study of mathematics among UA students, especially minority students, will continue.

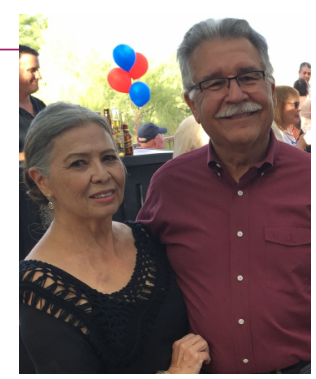

William (Bill) Yslas Vélez and his wife Bernice enjoy his retirement party from UA.
American Mathematical Society
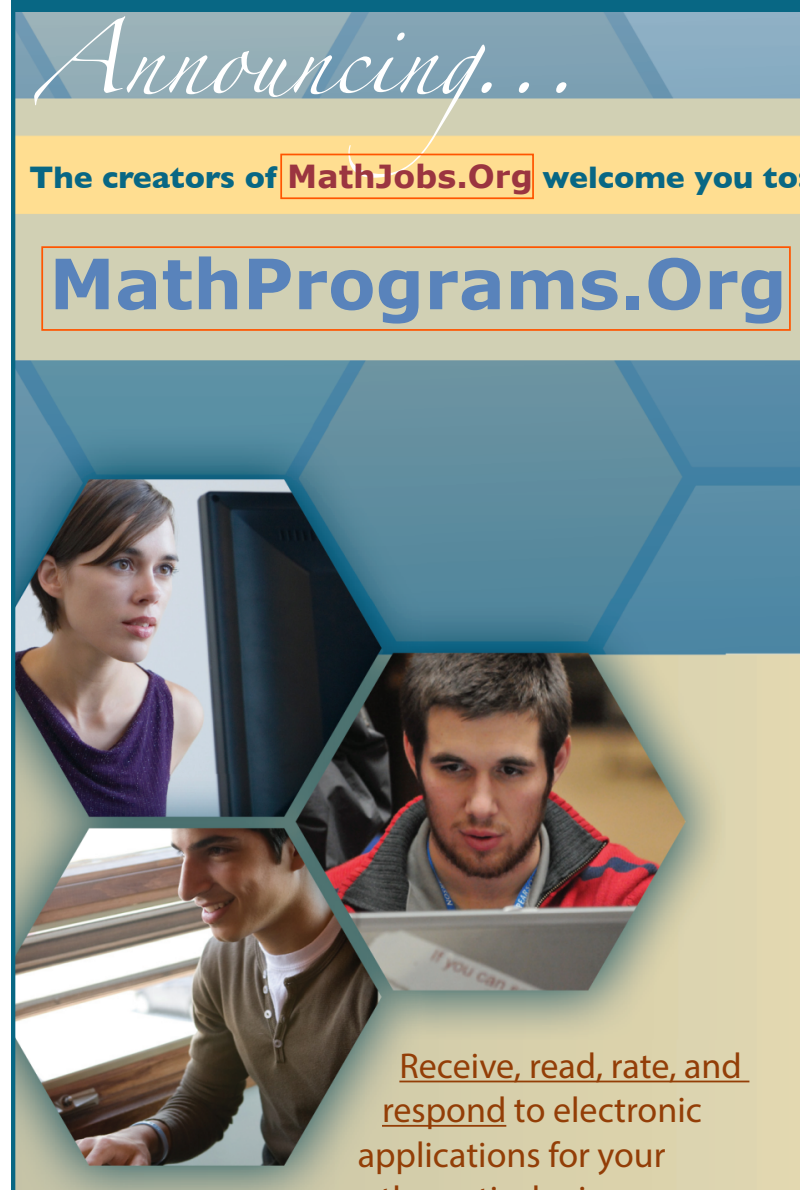

Receive, read, rate, and respond to electronic applications for your mathematical sciences programs, such as undergraduate summer research programs and travel grant competitions.

Customize your settings and control the application form; also set secure access for the admissions committee.

Enter program announcements for public display.

Download data to personal computers for use in word processing and spreadsheets or as a full permanent storage file.

\section{Service is FREE to applicants.}

Institutions pay annually for one program or for multiple programs.

AMS AMERICAN MATHEMATICAL SOCIETY 